\title{
Evaluation of Kinetic Adsorption Models in Aquatic Environment, Models of Lagergren and Ho et al.
}

\section{Zahra Askari ${ }^{1}$, Shayan Shamohammadi ${ }^{2}$, Ali Hasantabar-Amiri ${ }^{3}$, Kaveh Ostad-Ali-Askari ${ }^{{ }^{*}}$ Saeid Eslamian ${ }^{5}$, Vijay P. Singh ${ }^{6}$}

\author{
${ }^{1}$ Department of Water Engineering, Shahre-kord University, Shahre-kord, Iran \\ ${ }^{2}$ Department of Irrigation Engineering, Shahrekord University, Shahrekord, Iran \\ ${ }^{3}$ Department of Civil Engineering, Lenjn Branch, Islamic Azad University, Lenjan, Isfahan, Iran \\ $4^{4 *}$ Department of Civil Engineering, Isfahan (Khorasgan) Branch, Islamic Azad University, Isfahan, Iran \\ ${ }^{5}$ Department of Water Engineering, Isfahan University of Technology, Isfahan, Iran \\ ${ }^{6}$ Department of Biological and Agricultural Engineering \& Zachry Department of Civil Engineering \\ Texas A and M University, U.S.A \\ *Koa.askari@khuisf.ac.ir
}

Abstract: Heavy metal pollution has become one of the most cucial environmental obstacle today. The treatment of heavy metals is of special concern due to their refractoriness and resistence in the environment. In recent years, different procedures for heavy metal removal from wastewater have been widely studied.This paper revises the common procedures that have been applied to treat heavy metal wastewater and considers these techniques.Presently kinetic adsorption equations are widely used in adsorption processes. The main objective of the present research is to evaluate the linear and non-linear equations of the Lagergren and Ho et al. models in the kinetics of nickel adsorption by activated carbon. For this purpose, powdered activated carbon, the raw material of which is wood, was purchased from the "Merck" company (Germany). The optimum $\mathrm{PH}$ of the adsorption was obtained to be 6 . As well, the kinetics of adsorption showed that for the initial nickel concentration of $2.5,5,10,50$ and $125 \mathrm{mg} / \mathrm{L}$, equilibrium time was $40,75,120,150,50$ minutes respectively. The maximum removal efficiency of nickel in the initial concentration of $2.5 \mathrm{mg} / \mathrm{L}$ was obtained to be $89.6 \%$. The fitting of the four linear kinetic models of Ho et al. (1995), and its non-linear model, as well as the linear model ofkinetic data of adsorption at different concentrations showed that the non-linear model of Ho et al. (1995) better describes the kinetic data of nickel adsorption by activated carbon thanhis linear models. Comparison of the non-linear models of Ho et al. and Lagergren (1893) showed that in low concentrations the non-linear model of Ho et al., and in high concentrations non-linear model of Lagergren better describes the kinetic data of adsorption.First and second-order rate equations were pragmatic to etude adsorption kinetics.The most significant advantage of the offered model is its capability to predicate the balance time of adsorption, which is very essential to optimize the expense of the adsorption system design.The received consequences depict that the new model can analyze the experiential information very well.The equation is received clearly by changing the mass balance equation of a single step batch-type system into integrated first order rate equation. The proposed new formulation depends on maximum sorption (or removal) rather than equilibrium sorption, as given by Lagergren equation. The precise value of equilibrium sorption is not easy to describe in many cases, and it is exhibit that the modified formulation prepares better correlation with sorption data when the procedure is far from completion.A corrected formulation of the popular Lagergren pseudo first order rate equation is proposed.The equation is created clearly by changing the mass balance equation of a single step batch-type system into unified first order rate equation. The proposed new formulation depends on maximum sorption (or removal) rather than equilibrium sorption, as given by Lagergren equation. The precise value of equilibrium sorption is not simple to describe in many cases, and it is exhibited that the modified formulation provides better correlation with sorption data when the process is far from completion.

Keywords: Adsorption, Nickel, Linear and Non-linear Models, Activated Carbon, Kinetic Adsorption 
Evaluation of Kinetic Adsorption Models in Aquatic Environment, Models of Lagergren and Ho et al.

Table1. List of Abbrevations

$k \alpha$ : the rate constant

$V$ : the volume of the solution (L)

$k_{2}$ : the Sobkowsk and Czerwinski rate constant

$q_{t}$ : the amount of ion sorbed at time $(\mathrm{mg} / \mathrm{g})$

$q_{\infty}:$ the amount of sorption after an infinite time

$k_{1}$ : the adsorption constant $(1 / \mathrm{min})$

$q_{e}$ : the amount of nickel ion sorbed at equilibrium $(\mathrm{mg} / \mathrm{g})$

$q_{t}$ : the amount of ion sorbed at time $(\mathrm{mg} / \mathrm{g})$

$C_{0}$ : the initial concentration of metal ion $(\mathrm{mg} / \mathrm{L})$

$k_{2}$ : the adsorption constant (g/mg.min)

$c_{t}$ : the concentration of metal ion solution at time $\mathrm{t}(\mathrm{mg} / \mathrm{L})$

$n_{0}:$ the exchange capacity

$m$ : the adsorbent weight (gr)

$\theta$ : the fraction of surface which is sorbed by gas

$\alpha_{\beta}$ : The Blanchard et al. rate constant

\section{INTRODUCTION}

Studies on the adsorption of heavy metals from industrial wastewaters have seen a remarkable growth in recent years due to the increasing use of such pollutants. Based on the objectives of adsorption studies various models for the analysis of adsorption processes are selected and used. One of the important goals of such studies is to determine the time required for optimal adsorption in the solid-liquid system (Jonathan et al., 2009:616). The mechanism of adsorption process and its time is called adsorption kinetics (Royer et al., 2009:1213; Lima et al., 2008:536). Adsorption kinetics is affected by various factors, such as concentration of the sorbed material, amount, size and special surface area of the adsorbent, $\mathrm{pH}$ of solution and ambient temperature (Shamohammadi, Heydari, 1386:126). For the best-fitting of the adsorption kinetic data models of Ho et al. (1995) and Lagergren (1893) are more efficient (Jonathan et al., 2009:616), where two types of equations, linear and non-linear, are used. Lagergren's model does not necessarily show the actual nature of adsorption, so the capability by this model to analyze the adsorption data is doubtful (Schiewe et al., 2008:1896). Ho et al. (2006) examined and evaluated the linear and nonlinear behavior of the Ho et al. (1995) model. Their results showed that the nonlinear model is better fitted with the adsorption data and provides a better ability to determine the parameters of the model. In the Table 2 the corrections of the Ho et al. model of adsorption kinetics are showed (Ho, 2006: 119).

At present, more than $40 \%$ of the nickel found in the environment is produced by industrial plants and battery factories (Ajmal et al., 2001:117), that have a great role in contaminating the surface waters(Dursun et al., 2006:187). Nickel concentration in industrial wastewater ranges from 3.4 to $900 \mathrm{mg} / \mathrm{L}$ (Patterson, 1985:217). 
Evaluation of Kinetic Adsorption Models in Aquatic Environment, Models of Lagergren and Ho et al.

It is possible with the adsorbents, such as active carbon (Erdogan et al., Akbar Esma'ili and Samira Qasemi, 2009:1818), zeolite (Prasanth et al., 2008:735), clay (Pratik et al., 2007:216), and sawdust (Rafatullah et al., 2009:969), to adsorb nickelin high capacity. The main objective of this research is to evaluate the linear and nonlinear equation models of Ho et al. and Lagergren, as well as to examine the kinetic parameters of nickel adsorption by activated carbon.

Table2. Corrections of the Adsorption Kinetics Model of Ho et al.

\begin{tabular}{|c|c|}
\hline References & Linear form of the model \\
\hline Sobkowsk and Czerwinski (1974) & $\frac{\theta}{1-\theta}=\kappa_{2} t$ \\
\hline Ritchie (1977) & $\frac{q_{\infty}}{q_{\infty}-1}=\alpha t+1$ \\
\hline Blanchard et al. (1984) & $\frac{1}{n_{\odot}-n}-\alpha_{\theta}-k t$ \\
\hline Ho (1995) & $\frac{t}{q_{t}}=\frac{1}{x q_{e}^{2}}+\frac{1}{q_{e}} t$ \\
\hline
\end{tabular}

\section{Materials And Methods}

In this research a standard nickel solution (Nickel Titrisol) manufactured by the German Merc company was purchased and a solution was prepared with the concentration of $1000 \mathrm{mg} / \mathrm{L}$ (stock solution). In all of the experiments the volume of the solution used was $50 \mathrm{ml}$, based on the $250 \mathrm{ml}$ Erlenmeyer flask. The utensils were washed with acid and then with deionized water. All solutions were tested with Whatman filter paper grade 40. The $\mathrm{pH}$ was measured by $\mathrm{pH}$ meter (model PTR 79) and to adjust pH nitric acid and sodium hydroxide solutions were used. Measurement of ion adsorption was carried out by the Spectroquant meter of the German Merck company. During all of the experiments the room temperature was controlled to be in the range of 22 to $24^{\circ} \mathrm{C}$.

\section{Preparation of Adsorbent}

Powdered activated carbon, the raw material of which is wood, was purchased from the German Merck company. Some characteristics of the used activated carbon and its consisting elements are presented in Table 3.

Table3. Characteristics of Powdered Activated Carbon and its Consisting Elements

\begin{tabular}{|c|c|}
\hline Characteristics & Amount \\
\hline Amount of the dissolved ethanol & $0.2 \%$ \\
\hline Chloride & $0.01 \%$ \\
\hline Sulfate & $0.01 \%$ \\
\hline Lead & $0.005 \%$ \\
\hline Iron & $150 \mathrm{mg} / \mathrm{L}$ \\
\hline Amount of the dissolved hydrochloric acid & $1 \%$ \\
\hline
\end{tabular}

\section{Effect of the Optimal Adsorption PH}

In eight $100 \mathrm{ml}$ capacity Erlenmeyer flasks $1 \mathrm{~g} / \mathrm{L}$ of weighted adsorbent was put inside of each of the Erlenmeyer flasks. Then, a metal solution with a concentration of $10 \mathrm{mg} / \mathrm{L}$ (Jamali Paqal'e, 1388:76) was added to each of the Erlenmeyer flasks. Different $\mathrm{pH}$ values (ranging from 2 to 8) were examined. The solutions were placed on a shaker rotating at the speed of $150 \mathrm{rpm}$ (Aydin et al., 2008:37) in a controlled temperature for 12 hours (Babel et al., 2003:14). 
Evaluation of Kinetic Adsorption Models in Aquatic Environment, Models of Lagergren and Ho et al.

\section{Effect of Contact Time and Initial Nickel Concentration:}

Twelve Erlenmeyer flasks were picked and in each of them nickel solution with a concentration of $2.5 \mathrm{mg} / \mathrm{L}$ was poured. Also, the amount of 0.05 grams of activated carbon adsorbent was added to each of the Erlenmeyer flasks and they with an optimal pH were put on the rotating shaker at the speed of $150 \mathrm{rpm}$ for 5 to 240 minutes. This procedure was repeated with the concentrations of $5 \mathrm{mg} / \mathrm{L}, 10 \mathrm{mg} / \mathrm{L}, 50 \mathrm{mg} / \mathrm{L}$ and $125 \mathrm{mg} / \mathrm{L}$.

\section{Kinetic Adsorption Models}

Lagergren's model(1898): this model is expressed as a equation based on the adsorbent capacity $\frac{d q}{d t}=K_{1}\left(q_{e}-q\right)$. By integrating the previous equation and boundary conditions $(\mathrm{q}=0, \mathrm{t}=0$ and $\mathrm{q}=\mathrm{q}, \mathrm{t}=\mathrm{t})$, it was changed to equation $\ln \left(q_{e}-q\right)=\ln q_{e}-K_{1} t$, that may be rearranged to the non-linear form. Also its linear form is written as $\log \left(q_{0}-q_{x}\right)=\log q_{e}-\frac{k \varepsilon_{1}}{2.303} \pm$ equation In order to fit the linear models with the experimental data, $q_{t}$ and $\log \left(q_{e}-q_{t}\right)$ is written in front of $t$. In the linear form line slope $\frac{\pi_{1}}{2.303}$ and its y-intercept will be $\log q_{e}$. Therefore, it is possible to obtain $k_{1}$ and $q_{\mathrm{e}}$ from the slope and y-intercept of linear equation (Ho et al., 2002:797).

Ho et al. model (1995): this model is widely used in analyzing and examining kinetic adsorption data (Ho et al., 2001:241; Ho et al., 2000:189). It is possible to write this model in different linear forms (Makris et al., 2005: 4250; Duons et al., 2005:438; Wang et al., 2005:336; Janos et al., 2005:19). It has four linear forms (Yuh et al., 2006:119) (Table 4).

Differential form of the Ho et al. model (1996) is written as follows: $\frac{d q_{x}}{d t}=k_{2}\left(q_{e}-q_{t}\right)^{2}$. As well, for the boundary conditions ( $\mathrm{t}=0$ to $\mathrm{t}$ and $\mathrm{q}=0$ to $\mathrm{q}$ ) non-linear equation form is written like this: $q=\frac{q_{e}^{2}}{1+q_{e} k_{2} t}$

Table4. Linear Forms of Ho et al. Model

\begin{tabular}{|c|c|}
\hline Type of Equation & Linear Equation Form of Ho et al. \\
\hline 1 & $\frac{t}{q_{t}}=\frac{1}{\mathrm{k} q_{e}^{2}}+\frac{1}{q_{e}} t$ \\
\hline 2 & $\frac{1}{q_{t}}=\left(\frac{1}{\mathrm{k} q_{e}^{2}}\right) \frac{1}{t}+\frac{1}{q_{e}}$ \\
\hline 3 & $q_{t}=q_{e}-\left(\frac{1}{\mathrm{k} q_{e}}\right) \frac{q_{t}}{t}$ \\
\hline 4 & $\frac{q_{t}}{t}=\mathrm{k} q_{e}^{2}-\mathrm{k} q_{e} q_{t}$ \\
\hline
\end{tabular}

The linear equations of Ho and et al. model provide different amounts in determining the adsorption parameters (Ho, 2004:2115; Longhinoti et al., 1998:435; Kinniburgh, 1986:895). First type linear equation (see Table 4) is more known than the other types (Ho et al., 2006:119; Yuh at al., 2006:119). By fitting the models with the experimental data, in both linear and nonlinear forms, the coefficients of the Ho et al. model are obtained. Then $q_{\mathrm{t}}$ and $t / q_{\mathrm{t}}$ are written against $t$ respectively, and in this way constants $k_{2}$ and $q_{\mathrm{e}}$ are calculated. As well, it is possible to calculate the $q_{\mathrm{t}}$ by using the following equation $q_{t}=\frac{c_{o}-c_{t}}{m} \times v$.

\section{RESULTS AND Discussion}

\section{Determining optimal PH}

Environmental acidity, in which the adsorption process takes place, has a great influence on the absorption rate (Larous at al., 2005:483; Ahmad et al., 2008:127). Part of this effect is due to the adsorption of hydrogen 
Evaluation of Kinetic Adsorption Models in Aquatic Environment, Models of Lagergren and Ho et al.

ions (Jamali Paqal'e, 1388:76), which appear as competitors in the surface adsorption of cations (Addel Ghani et al., 2007:67; Srivastava et al., 2009:370). Figure 1 presents effect of $\mathrm{pH}$ on nickel absorption efficiency. The maximum absorption efficiency in $\mathrm{pH}=6$ equals to $79.24 \%$. The intensity of nickel adsorption from $\mathrm{pH}=2$ to $\mathrm{pH}=6$ is high and in $\mathrm{pH}=6$ reaches its maximum rate. From $\mathrm{pH}=6$ to $\mathrm{pH}=8$ adsorption intensity remains almost constant. The relatively rapid increase of adsorption efficiency in $\mathrm{pH}<6$ can be attributed to two factors: 1 . In low $\mathrm{pH}$ rates the amounts of $\mathrm{H}^{+}$ions found in solution, that compete with the nickel positive ions for the surface adsorption, their amount is enough; 2 . For each metal ion apt to hydrolysis there is a critical $\mathrm{pH}$ range point, at which the metal adsorption efficiency from a very small value reaches its maximum value. This value is called surface adsorption threshold (Kumar et al., 2006:104). Constant value in $\mathrm{pH}>6$ corresponds to the results of the reports of Vimal Chandra et al. (2006:257) and Semerijian (2009:155).

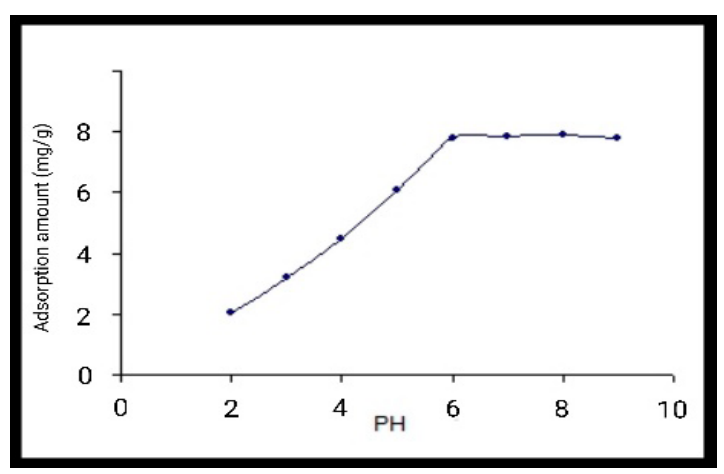

Fig1. Effect of PH on Nickel Adsorption Efficiency by Powdered Activated Carbon Adsorbent(Initial concentration of nickel - $10 \mathrm{mg} / \mathrm{L}$, contact time - 5 hours, amount of adsorbent $-1 \mathrm{~g} / \mathrm{L}$ )

\section{Kinetic Adsorption Experiments}

\section{Effect of Contact Time and Initial Concentration}

In Figure 2 the changes in the amount of nickel adsorption by the activated carbon adsorbent together with the time are presented. As can be seen, initially, the adsorption intensity rate is high in all concentrations, but over time, adsorption intensity decreases until finally it reaches a constant value. The period of time necessary for the adsorption amount to reach its maximum is called equilibrium time. At this point the maximum amount of adsorption occurs.

Maximum amount of adsorption in $2.5 \mathrm{mg} / \mathrm{L}, 5 \mathrm{mg} / \mathrm{L}, 10 \mathrm{mg} / \mathrm{L}, 50 \mathrm{mg} / \mathrm{L}$ and $125 \mathrm{mg} / \mathrm{L}$ concentrations is respectively $2.24 \mathrm{mg} / \mathrm{g}, 4.3 \mathrm{mg} / \mathrm{g}, 7.96 \mathrm{mg} / \mathrm{g}, 14.26 \mathrm{mg} / \mathrm{g}$ and $21.22 \mathrm{mg} / \mathrm{g}$.

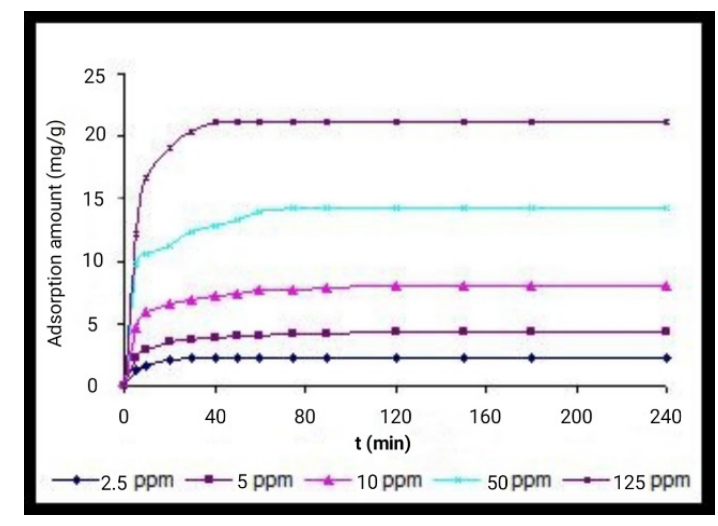

Fig2. Effect of Contact Time of Activated Carbon Adsorbent on Removing Nickel (Amount of adsorbent - $10 \mathrm{~g} / \mathrm{L}$ and $\mathrm{pH}=6$ ) 
Therefore, it may be concluded that for a certain amount of adsorbent by increasing nickel ion concentration from 2.5 to $125 \mathrm{mg} / \mathrm{L}$, the adsorption amount decreased from $89.6 \%$ to $21.22 \%$. These results are consistent with the results of studies performed by Jamali et al. (2008: 65).

Also, the results of the experiments of the effect of initial solution concentration on the equilibrium time of the nickel adsorption are shown in Figure 3.

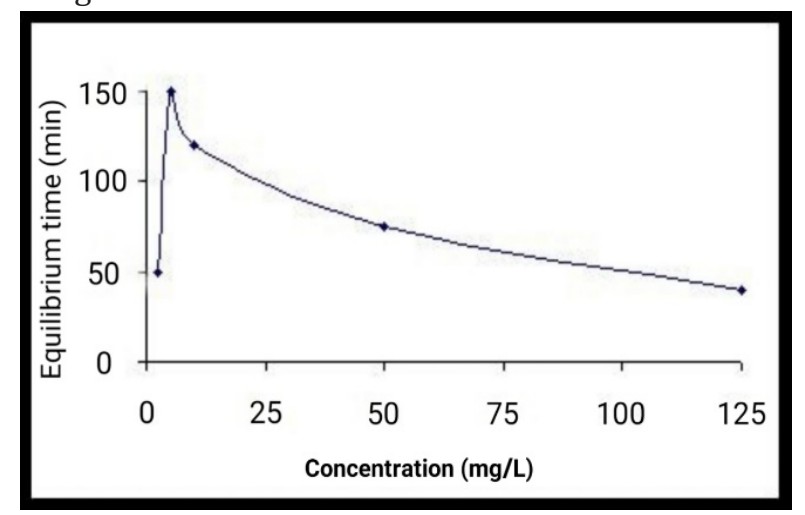

Fig3. Effect of Initial Nickel Concentration on Equilibrium Time by Powdered Activated Carbon

As can be seen, equilibrium time of nickel adsorption by activated carbon adsorbent in $2.5 \mathrm{mg} / \mathrm{L}, 5 \mathrm{mg} / \mathrm{L}, 10$ $\mathrm{mg} / \mathrm{L}, 50 \mathrm{mg} / \mathrm{L}, 125 \mathrm{mg} / \mathrm{L}$ respectively equals to $50,150,120,75,40$ minutes.

According to the above Figure, it can be said that by increasing the concentration of nickel solution from 5 to $125 \mathrm{mg} / \mathrm{L}$, and also by decreasing the concentration of solution from 5 to $2.5 \mathrm{mg} / \mathrm{L}$, the equilibrium time of the adsorption process decreases. By reducing the initial concentration of the solution, it is expected that the time to achieve equilibrium will be increased due to a decreased chance of metal contact with adsorbent. However, given that in low concentrations the amount of metal ions found in the solution is low, this limited amount of ion is absorbed by the pores of the adsorbent. Therefore, the time to reach the equilibrium decreases by decreasing initial concentration of nickel. In this case (when concentrations are low), the factor determining equilibrium time is the concentration of solution. In high concentrations, due to the high accumulation of metal ions around the adsorbent and increased chance of metal contact with the adsorbent, it takes a little more time for the adsorbent capacity to reach its saturation and the process to reach equilibrium.

Therefore, in this case also, the factor determining the equilibrium time is the adsorbent's capacity. These results are consistent with the results of the studies performed by Jamali (1387:71), Jamali Paqal'e (1388:88) and (Azizian, 2004:47).

\section{Kinetic Adsorption Equations}

The transformation of the non-linear model of Ho et al. to linear equations may lead to an increase in the error variance and standard least squares (Kinniburgh, 1986:895; Ho, 2004:2115).

Figures 4 and 5 present respectively the fitting of non-linear models of Lagergren and Ho et al., and Figures 6, 7, 8, 9, 10 present respectively the fitting of the linear models of Lagergren and Ho et al. As well kinetic parameters of the linear and non-linear equations adsorption of the Lagergren and Ho et al. models respectively are shown in Tables 5 and 6. The results show that the numerical values of the kinetic parameters of adsorption $q_{\mathrm{e}^{\prime}} k_{1}$ (in each of the four linear models of Ho et al., Type 1, 2, 3 and 4) differ significantly, which can be explained by their non-nonlinearregression coefficients. These results correspond to the studies performed by Yuh et al. (2006:119). Therefore, having a reliable non-linear model (Ho et al., 1995:1327), the usage of different linear equations of this model does not seem necessary.

American Research Journal of Civil And Structural Engineering Page 6 
Evaluation of Kinetic Adsorption Models in Aquatic Environment, Models of Lagergren and Ho et al.

As well, the results of the fitting of the non-linear models of Lagergren and Ho et al. (Fig. 6) show that, although both models describe the data by the accuracy of 95\%, the model of Ho et al. is more efficient for all concentrations used in the test. The reason of this might be due to the hypothesis of Ho et al. regarding the effect of the adsorbent capacity on the initial rate of adsorption (Jonathan et al., 2009:616). These results do not correspond to the results of Shamohmmadi and Heydari (1386:126), but is in correspondence with the results of the studies performed by Jamali at al. (1386:70), Jamali Paqal'e (1388:90), Jonathan et al. (2009:616), Mohama et al. (2009:12) and Ho (2004:2115).

Comparison of the non-linear models of Ho etal. with the Lagergren's model in different concentrations, presented in Table 6, shows that in low concentrations the Lagergren's model and in high concentrationsthe Ho et al. model has better regression coefficient, and therefore describes the data better. These results correspond to the results of the study performed by Azizian (2004:47).

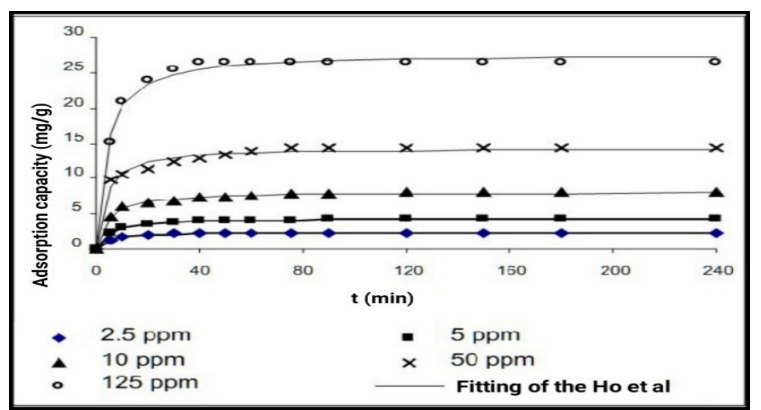

Fig4. Fitting of the Lagergren's non-linear with kinetic adsorption datamodel

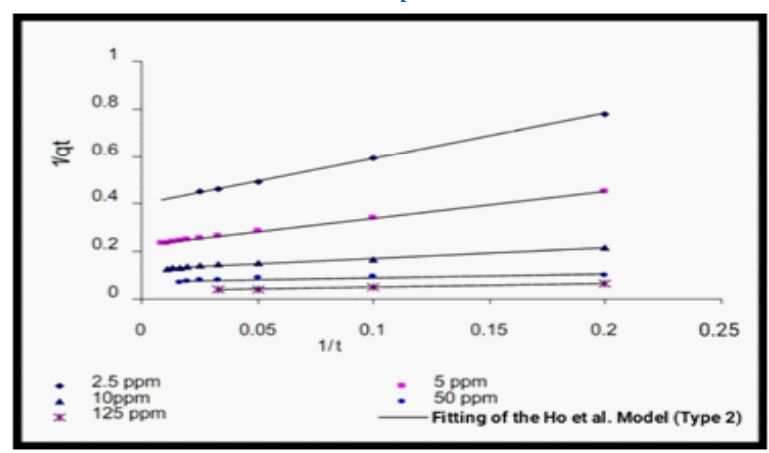

Fig6. Fitting of the Lagergren's linear model with kinetic adsorption data

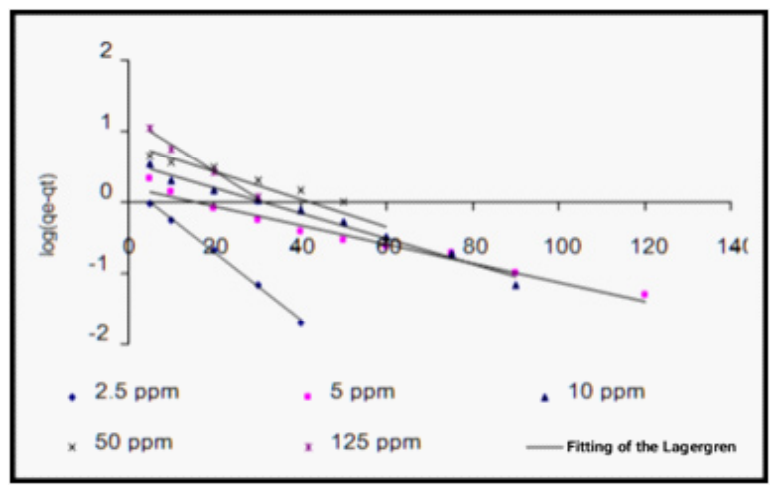

Fig8. Fitting of the Ho et al. Type 2 linear model with kineticadsorption data

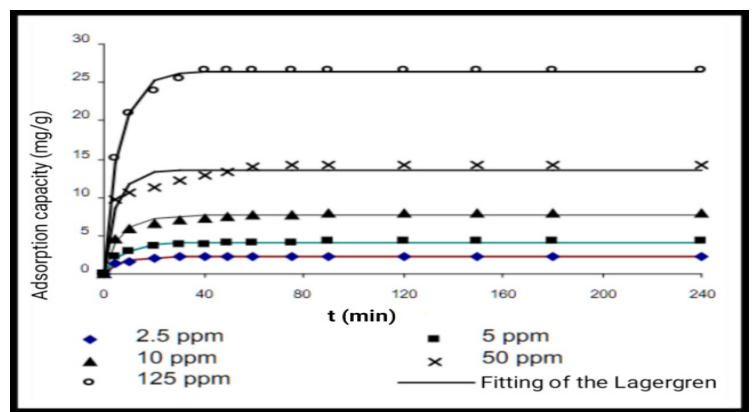

Fig5. Fitting of the Ho et al. non-linear model with kinetic adsorption data

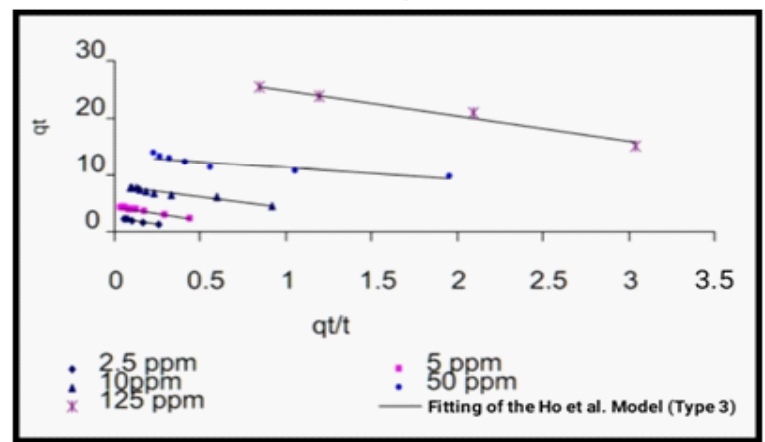

Fig7. Fitting of the Ho et al. Type 1 linear model with kineticadsorption data

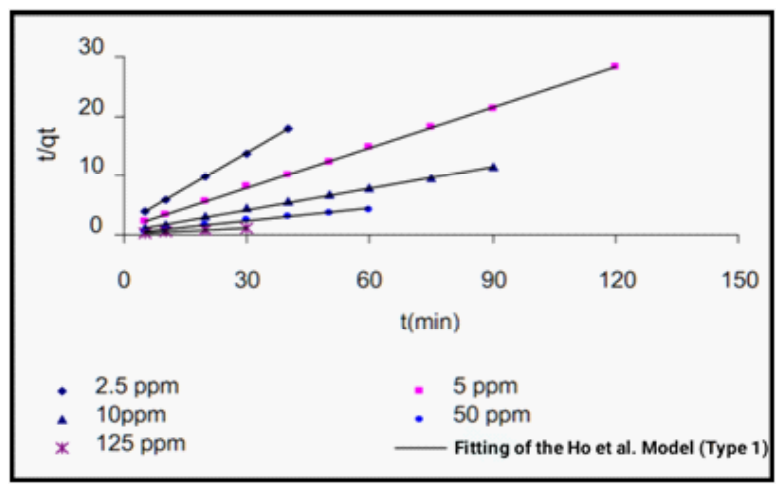

Fig9. Fitting of the Ho et al. Type 3 linear model with kineticadsorption data 
Evaluation of Kinetic Adsorption Models in Aquatic Environment, Models of Lagergren and Ho et al.

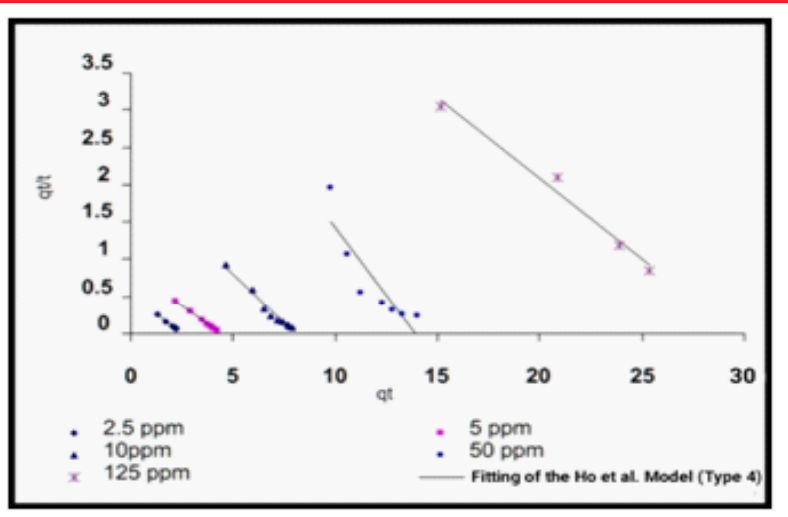

Fig10. Fitting of the Ho et al. Type 3 linear model with $t$ kinetic adsorption data

The coefficient of the Ho et al. model $\left(k_{2}\right)$ shows surface adsorption rate of the adsorbent before reaching equilibrium. The higher the coefficient, the greater is the surface adsorption rate of the metal ion by the adsorbent (Shahmohammadi Heydari, 1386:126). As is shown in Table 6, by increasing the solution concentration from 2.5 to $125 \mathrm{mg} / \mathrm{L}$, the coefficient $k_{2}$ of the Ho et al. non-linear model is reduced. These results correspond to the studies of Aksu (2008:112), Mane et al. (2007:390), Han et al. (2009:496) and Azizian et al. (2006:112). Rate of the coefficient $k_{2}$ by increasing concentration in the Langergren's model at first increases and later decreases (there is no linear relation). As it is seen, this is not a linear relation and therefore in this case the Lagergren's model has no good capacity in describing the data (Azizian, 2004:47). Thus, this result confirms the results of the comparison of the regression coefficients of the the Lagergren models and Hu et al. models.

Table5. Constants of the linear kinetic models for absorbing nickel by powdered activated carbon adsorbent

\begin{tabular}{|c|c|c|c|c|c|c|c|c|c|c|c|c|c|c|c|c|}
\hline \multicolumn{3}{|c|}{ Ho et al. (Type 4) } & \multicolumn{3}{|c|}{ Ho et al. (Type 3) } & \multicolumn{3}{|c|}{ Ho et al. (Type 2) } & \multicolumn{3}{|c|}{ Ho et al. (Type 1) } & \multicolumn{3}{|c|}{ Lagergren } & \multirow{2}{*}{$q_{e \exp }$} & \multirow{2}{*}{ 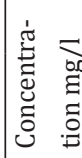 } \\
\hline$R^{2}$ & $q_{e}$ & $k_{2}$ & $R^{2}$ & $q_{e}$ & $k_{2}$ & $R^{2}$ & $q_{e}$ & $k_{2}$ & $R^{2}$ & $q_{e}$ & $k_{2}$ & $R^{2}$ & $q_{e}$ & $k_{1}$ & & \\
\hline 0.998 & 2.503 & 0.0831 & 0.1093 & 1.726 & 0.997 & 0.085 & 2.493 & 0.999 & 0.0835 & 2.501 & 0.999 & 0.0833 & 2.502 & 0.998 & 2.5 & 2.24 \\
\hline 0.998 & 4.4 & 0.0456 & 0.0306 & 1.643 & 0.969 & 0.0428 & 4.430 & 0.999 & 0.0428 & 4.391 & 0.999 & 0.0457 & 4.399 & 0.998 & 5 & 4.3 \\
\hline 0.969 & 8.035 & 0.0326 & 0.0414 & 3.667 & 0.989 & 0.025 & 8.244 & 0.999 & 0.0342 & 7.98 & 0.986 & 0.0338 & 7.999 & 0.969 & 10 & 7.96 \\
\hline 0.79 & 13.861 & 0.0265 & .0446 & 6.652 & 0.969 & 0.016 & 14.513 & 0.994 & 0.0364 & 13.368 & 0.848 & 0.0345 & 13.469 & 0.790 & 50 & 14.26 \\
\hline 0.981 & 29.632 & 0.0072 & 0.0882 & 15.649 & 0.883 & 0.008 & 29.06 & 0.999 & 0.007 & 29.85 & 0.992 & 0.0074 & 29.477 & 0.981 & 125 & 26.53 \\
\hline
\end{tabular}

Table6. Constants of the non-linear kinetic models for absorbing nickel by powdered activated carbon adsorbent

\begin{tabular}{|c|c|c|c|c|c|c|c|}
\hline \multicolumn{3}{|c|}{ Ho et al. } & \multicolumn{3}{|c|}{ Lagergren } & \multirow{2}{*}{$q_{\text {exp }}$} & \multirow{2}{*}{ 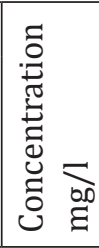 } \\
\hline$R^{2}$ & $q_{e}$ & $k_{2}$ & $R^{2}$ & $q_{e}$ & $k_{1}$ & & \\
\hline 0.993 & 2.244 & 0.114 & 0.985 & 2.226 & 0.1518 & 2.24 & 2.5 \\
\hline 0.996 & 4.411 & 0.004 & 0.977 & 2.344 & 0.1262 & 4.3 & 5 \\
\hline 0.997 & 8.097 & 0.003 & 0.966 & 7.619 & 0.158 & 7.96 & 10 \\
\hline 0.979 & 14.349 & 0.002 & 0.934 & 13.583 & 0.1958 & 14.26 & 50 \\
\hline 0.993 & 27.705 & 0.001 & 0.995 & 26.338 & 0.1601 & 26.53 & 125 \\
\hline
\end{tabular}




\section{CONCLUSIONS}

1. Non-linear model of Ho et al. (1995) better describes the kinetic data of nickel adsorption by activated carbon than their linear models.

2. In the non-linear model of Ho et al. (1995) in increasing concentration of nickel solution, adsorption rate is reduced and the equilibrium concentration on solid phase $\left(q_{\mathrm{e}}\right)$ is increased.

3. Comparison of the Ho et al. and Lagergren's non-linear models shows that in low concentrations the nonlinear model of Ho et al. and in high concentrations the Lagergren's non-linear model better describes the kinetic data of nickel adsorption by activated carbon.

4. Adsorption procedures can be modeled on the basis of phenomenological theories using conservation, equilibrium and transport kinetics equations.However many times an experiential procedure is followed using pseudo first order and pseudo second order models to explain adsorption kinetics. A relation between the kinetic constants of both models is insulated, being possible to reveal they exhibit very iffferent dependency with temperature whatever the porous structure of the adsorbent particle.Adsorption kinetic curves of the Lagergren's first-order (LFO) equation were classified into four areas pursuant to their ascending characteristics. Of the 85 adsorption procedures defined by Lagergren's first-order equation, $46 \%$ of the kinetic curves depended on zone II and $29 \%$ to zone III, these being good and fast.The standard models are found to be special states of the general adsorption-diffusion model for determined quantities of the dimensionless numbers. The kinetics of adsorption was described by applying Lagergren's pseudofirst order and pseudo-second order equations and the consequences have exhibited that the adsorption procedures follows pseudo-second order kinetics and the adsorption procedures belongs on both time and concentration.

5. The precise value of equilibrium sorption is not simple to describe in many cases, and it is exhibited that the modified formulation prepares better correlation with sorption information when the procedure is far from performance.In result, care must be taken when applying the shortcut procedure of pseudo first order expressions, taking into account their theoretical inconvenient attitudes.

6. A corrected formulation of the popular Lagergren pseudo first order rate equation is proposed.The equation is created clearly by changing the mass balance equation of a single step batch-type system into unified first order rate equation. The proposed new formulation depends on maximum sorption (or removal) rather than equilibrium sorption, as given by Lagergren equation. The precise value of equilibrium sorption is not simple to describe in many cases, and it is exhibited that the modified formulation provides better correlation with sorption data when the process is far from completion.The mechanistic route of the adsorption procedure was assess with intraparticle diffusion model. The trace of heat of adsorption of the adsorbate onto the adsorbent material was defined using the thermodynamic parameters and the reusability of the adsorbent materials was defined with desorption studies.

7. Adsorption has been demonstrated to be an great way to treat industrial waste sewages, offering important superiorities like the relatively inexpensive, accessibility, profitability, easy of action and performance.

\section{REFERENCES}

1. Jamali Paqal'e, A. 1388. Analysis of the process of copper adsorption from aqueous solution by sawdust, zeolite and activated carbon. MA thesis, Zabol University, page 76.

2. Shahmohammadi Heydari, Z. 1386. analysis of the effect of sodium bicarbonate concentration on increasing the capacity of crushed carbon adsorbent in removal of cadmium from aqueous environment. Journal of Sience. University of Ahvaz, No 17, page: 126.

American Research Journal of Civil And Structural Engineering Page 9 
Evaluation of Kinetic Adsorption Models in Aquatic Environment, Models of Lagergren and Ho et al.

3. Jamali Armandi, H. 1387. comparison of lead removal from aqueous environment by crushed shells and activated carbon. MA Thesis. Zabol University.

4. Abdel-Ghani, N. T., Hefny, M. and El-Chaghaby, G. A. F. 2007. Removal of lead from aqueous solution using low cost abundantly available adsorbents. Int. J. Environ. Sci. Tech. 4(1): 67- 73.

5. Ahmad, A., Rafatullah, M. and Qasimullah, S. 2008. Comparative Adsorption Studies for the Removal of Copper(II) from Aqueous Solution using Different Adsorbent. International Conference on Environmental Research and Technology.

6. Ajmal, M., Rao, R.A.K., Ahmad,R., Ahmad,J., 2000. Adsorption studies on citrus reticulate: removal and recovery of $\mathrm{Ni}(\mathrm{II})$ from electroplating wastewater. J. Hazard. Mater. B 79,117-131.

7. Esmaeil.A.i and Ghasem.S. 2009. Evaluation of the Activated Carbon Prepared of Algae Marine Gracilaria for the Biosorption of Ni (II) from Aqueous Solutions World Applied Sciences Journal 6 (4): 515-518, 2009. ISSN 1818-4952.

8. Aksu, Z. G. Karabayır.2008. Comparison of biosorption properties of different kinds of fungi for the removal of Gryfalan Black RL metal-complex dye, Bioresour. Technol. 99 (16) (2008) 7730-7741

9. Aydin, H., Bulut, Y. and Yerlikaya, C. 2008. Removal of copper(II) from aqueous solution by adsorption onto low- cost adsorbents. Journal of Environment Management, 87: 37- 45.

10. Azizian, S., and B. Yahyaei. 2006. Adsorption of 18-crown-6 from aqueous solutionon granular activated carbon: A kinetic modeling study. Journal of Colloid and Interface Science, 299: 112-115.

11. Azizian, S., 2004. Kinetic models of sorption: a theoretical analysis. J. Colloid Interface Sci. 276 (1), 47-52.

12. Babel S, Kurniawan TA. 2003. A research study on Cr (VI) removal from contaminated wastewater using natural zeolite. J Ion Exchange b; 14:289- 92.

13. Blanchard, G., Maunaye, M., Martin, G., 1984. Removal of heavy metals from waters by means of natural zeolites.Water Res. 18(12), 1501-1507.

14. Duons, T.D. M. Hoang, K.L. Ngugen, J.2005. Colloid Interface Sci. 287 (2005) 438.

15. Dursun. A.Y. 2006. A comparative study on determination of the equilibrium, kinetic and thermodynamic parameters of biosorption of copper(II) and lead(II) ions onto pretreated Aspergillus niger, Biochemical Engineering Journal 28 (2006) 187-195.

16. Erdog an , S. nal , Y. O, Akmil-Bas, ar C. , Bilmez-Erdemoglu b, S. Sarıcı.O zdemir, C Ko seog lu , E. I c, duygu G. 2005. Optimization of nickel adsorption from aqueous solution by using activated carbon prepared from waste apricot by chemical activation Applied Surface Science 252 (2005) 1324-1331.

17. JonathanFebrianto. A, Kosasih. J, Sunarso. Y, Hsu Ju. N, Indraswati. S, Ismadji.2009. Equilibrium and kinetic studies in adsorption of heavy metals using biosorbent: A summary of recent studies. Journal of Hazardous Materials 162 (2009) 616-645.

18. Janos, P. V. Smidova, J.2005. Colloid Interface Sci. 291 (2005) 19.

19. Han, R. J. Zhang, P. Han, Y.Wang, Z. Zhao, M. Tang,2009. Study of equilibrium, kinetic and thermodynamic parameters aboutmethylene blue adsorption onto natural zeolite, Chem. Eng. J. 145 (2009) 496-504.

20. Ho, Y.S., Wase, D.A.J., Forster, C.F., 1995. Batch nickel removal from aqueous solution by sphagnum moss peat. Water Res. 29 (5), 1327-1332

21. Ho, Y.S., Wang, C.C., 2004. Pseudo-isotherms for the sorption of cadmium ion onto tree fern. Process Biochem. 39 (6), 759-763.

American Research Journal of Civil And Structural Engineering

Page 10 
Evaluation of Kinetic Adsorption Models in Aquatic Environment, Models of Lagergren and Ho et al.

22. Ho, Y.S. J.C.Y. Ng, G. McKay. 2001. Sep. Sci. Technol. 36 (2001) 241.

23. Ho. Y. 2006. Second-order kinetic model for the sorption of cadmium onto tree fern: a comparison of linear and non-linear methods, Water Research 40 (2006) 119-125.

24. Ho, Y.S. J.C.Y. Ng, G. McKay.2000. Sep. Purif. Methods 29 (2000) 189.

25. Ho, Y.S. G. McKay.2002. Application of kinetic models to the sorption of copper(II) on to peat, Adsorption Sciences \& Technology 20 (2002) 797-815.

26. Kinniburgh, D.G., 1986. General purpose adsorption isotherms. Environ. Sci. Technol. 20 (9), 895-904.

27. Kumar, U., Bandypadhyay, M. 2006. "Sorption of cadmium from Aqueous Solution Using Pretreated Rice Hosk." Bioresour. Technol. 97, 104-109.

28. Lagergren, S. 1898. About the theory so- called adsorption of soluble substances. Kungliga Svenska Vetenskapsakademiens Handlingar, 24(4): 1- 39.

29. Larous, S., Meniai, A. H. and Bencheikh Lehocine, M. 2005. Experimental study of the removal of copper from aqueous solutions by adsorption using sawdust. Desalination. 185: 483- 490.

30. Lima, E.C. B. Royer, J.C.P. Vaghetti, N.M. Simon, B.M. da Cunha, F.A. Pavan, E.V.Benvenutti, R.C.Veses, C. Airoldi,. 2008. Application of Brazilian-pine fruit coat as abiosorbent to removal of reactive red 194 textile dye from aqueous solution.Kinetics and equilibrium study, J. Hazard. Mater. 155, p.536-550.

31. Longhinotti, E., Pozza, F., Furlan, L., Sanchez, M.D.N.D., Klug, M., Laranjeira, M.C.M., Favere, V.T., 1998. Adsorption of anionic dyes on the biopolymer chitin. J. Brazilian Chem. Soc. 9 (5), 435-440.

32. Makris, K.C. W.G. Harris, G.A. O'Connor, T.A. Obreza, H.A. Eliot.2005. Environ. Sci. Technol. 39 (2005) 4280.

33. Mane, V.S. I.D. Mall, V.C.2007. Srivastava, Kinetic and equilibrium isotherm studies for the adsorptive removal of Brilliant Green dye fromaqueous solution by rice Hosk ash, J. Environ. Manage. 84 (2007) 390400.

34. Mohana S., B.K. Acharya, D. Madamwar. 2009. Distillery spent wash: treatment technologies and potential applications, J. Hazard. Mater. 163 (2009) 12-25.

35. Patterson, J.W.,1985. Industrial Wastewater Treatment Technology, second ed. Butterworth, Boston,pp. 217-231.

36. Pratik M. Choksia, Vishal Y. Joshib.2007.Adsorption kinetic study for the removal of nickel (II) and aluminum (III) from an aqueous solution by natural adsorbents Desalination 208 (2007) 216-231.

37. Prasantha, K.P. Renjith S. Pillaia, H.C. Bajaja, R.V. Jasraa,_, H.D. CHongb, T.H. Kimb, S.D. Song. 2008. Adsorption of hydrogen in nickel and rhodiumexchanged zeolite X. I N T E R NATI O NAL JOURNA L OF HYDROGEN ENE RGY 33 (2008) 735 - 745

38. Rafatullah, M. SulaimanO. Hashim, R. Ahmad A. 2009. Adsorption of copper (II), chromium (III), nickel (II) and lead (II) ions from aqueous solutions by meranti sawdust Journal of Hazardous Materials 170 (2009) 969-977.

39. Ritchie, A.G., 1977. Alternative to the Elovich equation for the kinetics of adsorption of gases on solids. J. Chem. Soc. Faraday Trans. I 73 (10), 1650-1653.

40. Royer B, Cardoso NF, Lima EC, Vaghetti JCP, Simon NM, Calvete T, Veses RC. 2009. Applications of Brazilian pine-fruit shell in natural and carbonized forms as adsorbents to removal of methylene blue from aqueous solutions-Kinetic and equilibrium study. J Hazard Mater; 164: 1213-1222.

American Research Journal of Civil And Structural Engineering

Page 11 
Evaluation of Kinetic Adsorption Models in Aquatic Environment, Models of Lagergren and Ho et al.

41. Semerjian, L. 2009. Equilibrium and kinetics of cadmium adsorption from aqueous solutions using untreated Pinus halepensis sawdust Journal of Hazardous Materials, (2009) 155-163.

42. Schiewer S., S.B. Patil.2008. Pectin-rich fruit wastes as biosorbents for heavy metal removal: equilibrium and kinetics, Bioresource Technology 99 (2008) 1896-1903.

43. Srivastava, V. C., Mall, I. D. and Mishra, I. M. 2009. Competitive adsorption of cadmium(II) and nickel(II) metals ions from aqueous solution onto rice Hosk ash. Chemical Engineering and Processing. 48: 370379.

44. Sobkowsk, J., Czerwin' ski, A., 1974. Kinetics of carbon dioxide adsorption on a platinum electrode. J. Electroanal. Chem. 55 (3), 391-397.

45. Vimal Chandra, S. 2006. Characterization of mesoporous rice Hosk ash (RHA) and adsorption kinetics of metal ions from aqueous solution onto RHA, Indra Deo Mall *, Indra Mani Mishra Journal of Hazardous Materials B134 (2006) 257-267.

46. Wang, S. L. Li, H. Wu, Z.H. ZHo, J.2005. Colloid Interface Sci. 292 (2005) 336.

47. yuh, shan ho.2006. second-order kinetic model for the sorption of cadmium onto tree fern: a comparison of linear and non-linear methods.j. water reseach 40(200+6)119-125.

48. Yanbo Zhou, Ruzhuang Zhang, Ke Chen, Xuanran Zhao, Jun Lu.2017. Enhanced adsorption and photodegradation of bisphenol A by $\beta$-cyclodextrin modified pine sawdust in an aquatic environment. Journal of the Taiwan Institute of Chemical Engineers, Volume 78, September 2017, Pages 510-516.

49. Carmalin Sophia A., Eder C. Lima.(2018). Removal of emerging contaminants from the environment by adsorption.Ecotoxicology and Environmental Safety, Volume 150, 15 April 2018, Pages 1-17.

50. Y.H. Magdy, H. Altaher.(2018).Kinetic analysis of the adsorption of dyes from high strength wastewater on cement kiln dust.Journal of Environmental Chemical Engineering, Volume 6, Issue 1, February 2018, Pages 834-841.

51. Antonio Zuorro, Gianluca Maffei, Roberto Lavecchia.(2017).Kineticmodeling of azo dye adsorption on nonliving cells of Nannochloropsis oceanica.Journal of Environmental Chemical Engineering, Volume 5, Issue 4, August 2017, Pages 4121-4127.

52. Џin Qian, Kun Li, Peifang Wang, Chao Wang, Bianhe Lu.(2017). Effects of carbon nanotubes on phosphorus adsorption behaviors on aquatic sediments. Ecotoxicology and Environmental Safety,Volume 142, August 2017, Pages 230-236.

53. Sudeshna Saha, Hirakendu Basu, Rakesh Kumar Singhal, Mehzabin Vivek Pimple.(2017). Titania coated silica microsphere functionalized with potassium ferrocyanide impregnated in calcium alginate for efficient removal of Cs from aquaticenvironment. Journal of Environmental Chemical Engineering, Volume 5, Issue 5, October 2017, Pages 5187-5195.

54. Lida Rafati, Mohamad Hassan Ehrampoush, Amir Abbas Rafati, Mehdi Mokhtari, Amir Hossein Mahvi. Modeling_of adsorptionkinetic and equilibrium isotherms of naproxen onto functionalized nano-clay composite adsorbent.Journal of Molecular Liquids, Volume 224, Part A, December 2016, Pages 832-841.

55. Gang Jin, Yujin Eom, Tai Gyu Lee.(2016). Removal of Hg(II) from aquatic environments using activated carbon impregnated with humic acid. Journal of Industrial and Engineering Chemistry, Volume 42, 25 October 2016, Pages 46-52.

American Research Journal of Civil And Structural Engineering Page 12 
Evaluation of Kinetic Adsorption Models in Aquatic Environment, Models of Lagergren and Ho et al.

56. You-Ting Meng, Yuan-Ming Zheng, Li-Mei Zhang, Ji-Zheng He.(2009). Biogenic Mn oxides for effective adsorption of $\mathrm{Cd}$ from aquatic environment. Environmental Pollution, Volume 157, Issues 8-9, AugustSeptember 2009, Pages 2577-2583.

57. Manisha Sharma, Satyajit Hazra, Soumen Basu.(2017). Kinetic and isotherm studies on adsorption of toxic pollutants using porous ZnO@SiO2 monolith. Journal of Colloid and Interface Science, Volume 504, 15 October 2017, Pages 669-679.

58. Ponnusamy Senthil Kumar, Sunita J. Varjani, Subburaj Suganya.(2018). Treatment of dye wastewater using an ultrasonic aided nanoparticle stacked activated carbon: Kinetic and isotherm modelling. Bioresource Technology, Volume 250, February 2018, Pages 716-722.

59. Hirakendu Basu, Rakesh Kumar Singhal, Mehzabin Vivek Pimple, Sudeshna Saha.(2018). Graphene oxide encapsulated in alginate beads for enhanced sorption of uranium from different aquatic environments. Journal of Environmental Chemical Engineering, Volume 6, Issue 2, April 2018, Pages 1625-1633.

60. Wojciech Konicki, Małgorzata Aleksandrzak, Ewa Mijowska.(2017). Equilibrium, kinetic and thermodynamic studies on adsorption of cationic dyes from aqueous solutions using graphene oxide. Chemical Engineering. Research and Design, Volume 123, July 2017, Pages 35-49.

61. C. Femina Carolin, P. Senthil Kumar, A. Saravanan, G. Janet Joshiba, Mu. Naushad.(2017). Efficient techniques for the removal of toxic heavy metals from aquatic environment: A review. Journal of Environmental Chemical Engineering, Volume 5, Issue 3, June 2017, Pages 2782-2799.

62. Malihe Fouladgar, Masoud Beheshti, Hassan Sabzyan.(2015). Single and binary adsorption of nickel and copper from aqueous solutions by $\gamma$-alumina nanoparticles: Equilibrium and kinetic modeling. Journal of Molecular Liquids, Volume 211, November 2015, Pages 1060-1073.

63. Chengyu Chen, Weilin Huang.(2017). Aggregation kinetics of nanosized activated carbons in aquatic environments. Chemical Engineering Journal, Volume 313, 1 April 2017, Pages 882-889.

64. Yongbing Cai, Yuting Mi, Hua Zhang.(2016). Kinetic modeling of antimony(III) oxidation and sorption in soils. Journal of Hazardous Materials, Volume 316, 5 October 2016, Pages 102-109.

Citation: Zahra Askari, Shayan Shamohammadi, Ali Hasantabar-Amiri, Kaveh Ostad-Ali-Askari, Saeid Eslamian, Vijay P. Singh, "Evaluation of Kinetic Adsorption Models in Aquatic Environment, Models of Lagergren and Ho et al.", American Research Journal of Civil and Structural Engineering, vol 2, no. 1, pp. 1-13.

Copyright (c) Zahra Askari, Shayan Shamohammadi, Ali Hasantabar-Amiri, Kaveh Ostad-Ali-Askari, Saeid Eslamian, Vijay P. Singh, This is an open access article distributed under the Creative Commons Attribution License, which permits unrestricted use, distribution, and reproduction in any medium, provided the original work is properly cited. 